\title{
A INFLUÊNCIA DA COMUNICAÇÃO CORPORATIVA NA MANIFESTAÇÃO DA LOUCURA ORGANIZACIONAL
}

\section{THE INFLUENCE OF CORPORATE COMMUNICATION IN EXPRESSION OF ORGANIZATIONAL MADNESS}

\author{
Monica Maria Martins de Souza $a^{1}$ \\ Doutorado em Comunicação e Semiótica \\ Faculdade ENIAC \\ Ruy Guérios \\ Mestrando em Engenharia de Produção \\ Faculdade ENIAC
}

\section{RESUMO}

A investigação acerca da comunicação interna na empresa e a loucura corporativa têm por objetivo analisar a relação entre os homens, o trabalho e a loucura. A relação vivenciada no espaço organizacional é orquestrada pela comunicação interna da empresa que, através das normas internas e externas, define atitudes e rege a atividade laboral. Submetidos às pressões das normas, os homens entram em conflito e enredados por uma das raízes da cultura, os estados alterados de consciência, se perdem de si mesmos resvalando o universo da loucura real ou imaginária.

Palavras-chave: comunicação, trabalho, loucura.

\begin{abstract}
The purpose of this work the enterprise's internal communications and the corporative madness is to analyze the relationship among people, employment and madness. The internal and external rules and communications of the companies define attitudes and the labor activity in a way that orchestrate the relations among employees. Submitted to the pressure of rules, people get into conflicts and get so upset that they can become mad, being madness one of the roots of culture. People can loose, in this process, their conscience, or the ability to distinguish reality from imagination.
\end{abstract}

Key words: Communication, work, madness.

\footnotetext{
${ }^{1}$ Autor para correspondência: Faculdade ENIAC - R. Força Pública, 89 - Centro, Guarulhos - SP, Brasil, 07012-030. 


\section{1 - INTRODUÇÃO}

Esta investigação analisa o sentido simbólico do trabalho no âmbito social, cultural e organizacional. Observa o seu papel na criatividade humana e a forma como essa criatividade desenvolve estratégias para suportar coerções e adaptar-se às mudanças. Assim o processo do trabalho dentro das organizações será visto sob o prisma da teoria da mídia. O foco estará voltado para a forma como esse homem reage às pressões nessa relação carregada de simbolismos que marca os corpos e a corporação. O processo do trabalho será então considerado como o elo que alimenta o vínculo entre homens e empresa para que essa possa atingir o lucro que é a sua meta. Esse vínculo liga o homem e a empresa e é regido pela comunicação interna que regulamenta as normas (internas e externas) que determinam o percurso dos corpos que neste espaço, representam papéis. Nessa representação os atores contracenam entre si governados pela missão corporativa que busca e precisa do homem para atingir a sua lucratividade. Esse fator, porém, não é explicito nem propagado no espaço corporativo, além de ser mascarado pela filosofia humanista que aí é divulgada. Pela presença da máscara aqui, se pode observar que a investigação da comunicação nunca será desvinculada da arte, da mitologia, das religiões, das lendas e das manifestações arcaicas. A empresa é, portanto, o espaço da presença arcaica e pontual dos elementos e dos indícios que marcam o funcionamento da comunicação. Nela não se pode conceber os processos comunicativos como mecanismo, mas, manifestação histórica da alma humana, como cultura humana. Essa manifestação se faz presente nas representações dos papéis organizacionais que serão analisados a seguir e neles se pode perceber a memória das histórias passadas e futuras se entremeando no espaço corporativo de acordo com MORIN (1990).

Esse espaço se torna um palco de representações simbólicas - os papéis - balizadas pela cultura, mitos e crenças, e nele contracenam culturas diferentes - da empresa e do funcionário em uma relação na qual são construídos os vínculos humanos e corporativos. Essa construção ocorre durante a representação dos papéis que a empresa estabelece que sejam interpretados pelos seus atores - os funcionários.

Nesse jogo de cena a empresa define para os homens atitudes e comportamentos, estabelece limites, e impõe metas a serem cumpridas. Esse procedimento é fundamental para que ela possa consolidar os seus objetivos financeiros. Na busca desses objetivos, a comunicação interna transforma esse território em arena de coerção mantendo, aí, os funcionários. Para que isso seja possível a empresa captura deles as necessidades reais e possíveis de acordo com Cassirer (1994), sendo as reais, as necessidades básicas de sobrevivência, e as possíveis, as necessidades de realização.

$\mathrm{Na}$ busca da realização e submetidos às pressões exercidas pela cultura corporativa, um percentual desses funcionários pode entrar em conflito, e nas situações limítrofes de desconforto serão capazes de apresentar atitudes características das psicopatologias mais diversas, que denunciam um comportamento às raias da loucura.

\section{2 - O ESPAÇO SIMBÓLICO DA EMPRESA: CONSTITUIÇÃO E REPRESENTAÇÃO}

"Lo que llamamos realidad y experimentamos como tal está cargada de cosas que estan en lugar de otras cosas distintas de lo que ellas son...” Pross (1980:13).

É pensando uma realidade simbólica que será tratada a atividade dos homens no processo corporativo, e as consequências da sua adaptação nesse espaço carregado de simbolismo. Ele é o palco da produção do trabalho, orquestrado pela comunicação corporativa, composta de normas que determinam, atitudes e comportamentos. Ela é ritualizada, estabelece sanções e premiações para consolidar a ordem e determinar a participação regular dos seus membros integrando-os (Pross,1980:85). Nesse espaço os funcionários são atores que transformam o texto mítico - a 
norma, em trabalho, interpretando-o através da representação de papéis ${ }^{2}$. E isso custa a eles a própria identidade.

A corporação é o lugar de intercessão em que se intercruzam tempo, espaço, mitologia, realidade e imaginação. É o "espaço de vida" das pessoas na vida contemporânea. Lugar em que duas ou mais pessoas trabalham juntas e de modo estruturado para alcançar objetivos específicos. Esses objetivos atendem à corporação: lucro para os seus acionistas, e bens ou serviços para a sociedade. E aos homens, que só nesse espaço atendem ao que justifica as suas existências - a necessidade de realização e reconhecimento: projeção social, status, e promoção. $\mathrm{O}$ espaço corporativo é regido por dois tipos de normas: as explícitas - missão, filosofia e política, contidas no manual de procedimentos que determina o que se faz na empresa, o que, como, onde e quando. A CI - circular interna; cartazes; quadros de aviso; emblemas, e fotos que anunciam a presença subjetiva do estreito espaço entre $\operatorname{corpos}^{3}$ e corporação. E as normas implícitas - contrato tácito, que não será objeto dessa pesquisa. Para $\operatorname{Samain}^{4}$, a corporação é a soma das atividades coordenadas de numerosos indivíduos. Essas atividades coordenadas produzem resultados amplamente superiores a si mesmos, em seu âmbito e complexidade. E eles são obtidos como resultado do empenho de cada atividade individual. Essas atividades são as coordenadas pelas normas que estabelecem os papéis necessários ao desenvolvimento do processo produtivo.

\section{3 - AS REPRESENTAÇÕES HUMANAS NO TRABALHO: PORTA DE ENTRADA DA LOUCURA}

Interessado em atender seus objetivos, e pressionado para atender aos objetivos da corporação, o homem se afasta de si mesmo e se imanta da identidade corporativa. Ele cria com ela uma simbiose tornando-se quase tão mecânico quanto as técnicas e as máquinas com as quais convive. Para tornar isso menos doloroso, ele encontra um viés comunicativo - a dissimulação, que o anula. Sobre isso Lucien Sfez diz que onde a política tradicional da comunicação fracassa, a própria comunicação estabelece algo em comum que ele esclarece, valendo-se de uma citação de Baudrillard:

Todos nós somos prisioneiros da espiral comunicativa, e não podemos escapar a ela. Se nos entregamos a ela nada podemos fazer nem dizer. Todos os nossos atos e enunciados são prisioneiros da armadilha que a denunciam. Agir ou escrever é reforçar a armadilha como os movimentos desordenados dos que se afundam em areia movediça. Assim nas relações humanas reina soberana a representação, ou o delírio. “... eu creio exprimir o mundo de máquina que me representa, mas é ele que se exprime em meu lugar”. Eu tenho a ilusão de ser e ver - Metáforas, pois o sujeito só existe através do objeto técnico que lhe atribui seus limites. Frankenstein é o duplo do dr. Frankenstein, o outro si com atributos do sujeito humano, a quem empresta sentimento e afeto (Sfez, 1994: 13-75).

Esse comportamento dissimulado, esse outro de si que o homem deixa manifestar, é uma adaptação. Ele pratica a dissimulação para evitar a punição, evitar crítica ou promover aceitação. Isso pode ocorrer de forma tanto consciente, quanto inconsciente. Essa dissimulação, embora pareça perfeita, custa ao homem um esforço psíquico, quase um sofrimento, que o denuncia. Quando com ela atua, o homem manifesta atitudes antagônicas porque na realidade ele está negando comportamentos estabelecidos. Um jogo performático, em que seu comportamento alienado confunde-se com o de um esquizofrênico. Deleuze em um estudo sobre "capitalismo e esquizofrenia" traz uma referência de Bateson que auxilia na compreensão dessa questão: segundo ele , "a esquizofrenia não é produto puro do cérebro, como acredita alguns psiquiatras, mas fruto de um sistema familiar ou social".

Bateson chama de "double bind" a emissão simultânea de dois tipos de mensagens que se contradizem entre si. Um exemplo é o pai que diz ao filho: anda critica-me, mas deixando perceber que qualquer crítica efetiva, ou 
pelo menos um certo gênero de crítica seria muito mal recebida. Bateson pensa que esta é uma situação particularmente esquizofrenizante, e interpreta-a como um "non-sens" dentro da perspectiva da teoria dos tipos de Russell ${ }^{21}$ o double bind, o duplo impasse, é uma situação corrente e edipianizante por excelência. E é nesse sentido que Édipo deve ser apresentado como uma série ou como oscilando entre dois pólos, que são a identificação neurótica, e a interiorização dita normativa. Mas o Édipo, o impasse duplo, está em ambos os lados. E se aqui um esquizofrênico se produz como entidade é por ser o único meio de escapar a essa via dupla.

Nela a normatividade não oferece mais saídas que a neurose, e a solução não está menos entravada que o problema. Então refugiamo-nos no corpo sem órgãos (Deleuze, 1966:83).

É exatamente esse corpo sem órgãos que historicamente procura se refugiar da punição e para isso cria estratégias para se ocultar ou ocultar seus atos, que vai para a corporação.

Segundo Baitello (1999) "o corpo do homem é um corpo de memória e de história, que constrói cenários, e histórias pregressas e progressas” - um corpo psicossomático de temporalidade que se apropria do tempo e do espaço, e quando vai para a corporação se apropria também da identidade corporativa. Ignorado como corpo cultural pela corporação que o submete, por ser ignorado, desse lugar ele responde alienado. Esse corpo vive um momento de confusão e conflito e age "voluntariamente" com a intenção de distorcer os conceitos que nele reinaram até então. Deixa de ser ele mesmo, um corpo de vida e de cultura, enlouquece, delira e se transforma em representação de si mesmo. E para adequar-se à corporação, ele permite que interfiram em suas histórias, apaguem parte de seus arquivos e com o seu consentimento promovam a destruição do seu mundo simbólico. De posse dos novos códigos, os corporativos, ele cria para si outros significados da corporação, entra dentro deles e os extrapola, ou seja, os reescreve. Em Sfez encontra-se uma citação de Sartre e Barthes, que ilustra esse processo:

...o receptor ao ler o texto o refaz, e a sua maneira a sua leitura é na verdade uma reescritura. ... essa sutileza da realidade ficcional é uma hibridização carregada de características de dupla criação; a fabricação, o meio de comunicação e o receptor tecem os vínculos com imagens mentais, o pensamento, e sua liberdade criativa. Assim ele recompõe o texto com o seu olhar, adequando-o ao seu mundo, dentro da sua possibilidade (Sfez 1994: 98).

A reescritura dos seus significados da norma é uma possibilidade dos homens submetidos às normas corporativas. Na teologia a teoria mata o corpo para ganhar o que chama de verdadeiro corpo que é a alma. Para atingir a ascensão social, o homem inserto na corporação permite a morte do seu corpo - mídia primária, para ganhar o corpo corporativo - corpo inscrito pela marca do outro. Preço que ele paga para ganhar a sanção positiva, um ato político. Com relação a esse ato político Sfez (1994:37) faz a seguinte colocação: “a política não está apenas nos poderes, na ideologia, na técnica, na organização social e nas rupturas - está em nossas utopias e visões de mundo que se enfrentam em cada um de nós, em lutas contra nós mesmos - de ecos ensurdecidos".

Sobre esse enfrentamento - No palco corporativo acontece a dinâmica representação dos homens no exercício de transformação da norma em trabalho. O primeiro passo que exige a sua submissão é preço alto que ele escolhe pagar. Porém quando ele se submete vende a sua alma ao diabo, constrói um cenário e entra dentro dele. Para evitar o sofrimento, incorpora Lethes, o esquecimento de si mesmo para atuar na corporação. Dessa forma o homem atende a corporação alimentando a sua história e dela sendo cúmplice. Os processos que nela se cumprem acontecem através dos seus corpos. Corpos sedados de si canalizando a energia corporativa titânica ${ }^{26}$, e realizando suas metas.

Do ponto de vista das relações titânicas as corporações se transformam em espaço de relações fatais conduzidas pelo despotismo, irracionalidade e a violência dos deuses primitivos. As forças primitivas atuam nos homens com a sua permissão quando se submetem. Nesse espaço em que essas forças vigoram não são da lei e da ordem, dos princípios e da benevolência, mas as 
primitivas arcaicas, da tirania das normas.

O cotidiano corporativo é uma luta de titãs com o qual o homem se depara. E quando se entrega às normas sede ao titanismo. Essa entrega é uma escolha individual, depende da sua consciência ao lidar com o fenômeno. Entrega-se aquele que se deixa levar cegamente pelos seus desejos e necessidades. De acordo com a Profa. Malena Segura Contrera "Todo arquétipo coletivo, quando entra em ação, provoca um rebaixamento natural da capacidade critica $e$ intelectual do homem e o mobiliza. ${ }^{27}$ ". A força das normas corporativas, aliadas às necessidades de realização dos homens e ao seu desejo de pertença, o atordoa e o faz cego à sua identidade. Nesse estado alterado de consciência ${ }^{28}$ ele se entrega ao titã corporação e para ele se disponibiliza. Dessa forma contracena no palco corporativo o trabalho e a loucura. Na medida em que a loucura paga pelo senso, fracassa a identidade. É um tempo despedaçado em si mesmo, sendo dominado além de medida: um tempo alienado em que o homem, fragmentado, se perde. (Loucura - Kamper www.cis.org.br)

\section{4 - A LOUCURA CORPORATIVA}

Ele se perde na tentativa de atender a si e ao outro. Nesse processo, muito do que compunha o seu padrão de valores permanece, mas o que mantém a sua unidade depois das adaptações e modificações, nem sempre é a sanidade. Prisioneiros da espiral comunicativa, armadilha que segundo Baudrillard denunciam o homem, e da qual não podem escapar. Cerceados pela espiral de Ananke e Cronos que espremem os seus corpos com as angústias e necessidades da vida, eles se alienam. Ameaçados por Cronos e pela sua foice do tempo, do destino e da morte eles se desesperam. Assim desesperados jogados na panóptica estratégia arquitetônica da corporação, os corpos dos homens ficam permanentemente condenados à visibilidade. Desta forma, totalmente impotentes, seus corpos refletem sem ter como e onde se esconder, e nessa condição, dia e noite representam. Segundo Kamper, quanto mais visibilidade menos propriocepção, sem saber reagir o homem gradativamente vai perdendo o seu corpo para a corporação. E sem o seu corpo nada mais lhe resta.

A construção do corpo corporativo implica na destruição do corpo da história cultural carregado de mitos, crenças, ideologias, jogos, utopias e religião vinculados ao imaginário. Os corpos corporativos são corpos marcados por cicatrizes da corporação e contam a sua história. Esse corpo surge como consequência da adaptação do mundo simbólico do homem à norma corporativa a qual ele se submete. Assim a corporação possui o funcionário transformado em imagem de si mesma, e decide o seu destino. Esse duplo poder sobre aquele que deixa de ser sujeito de si mesmo o intrapola. Essa é a opressão mais sutil porque conta com a cumplicidade do oprimido. Dessa forma a loucura que é historicamente a sombra da razão se instala e se alimenta de uma fonte comum. Essa loucura é o inicio de um percurso, o começo de uma viagem programada pelo próprio viajante. Isso porque do ponto de vista da cultura, a loucura está relacionada aos textos culturais construídos pelo próprio homem, autor da norma corporativa ou cúmplice dela. $\mathrm{O}$ substrato secreto do texto que se manifesta é de um tempo não vivido. Por detrás da história da dupla; razão-loucura ${ }^{30}$ aparece a efetividade de uma imaginação próxima à ventura, e de consequências poderosas e irreversíveis. Com relação a esse processo Kamper tem a seguinte definição:

A loucura é a sombra da norma; e contém, mesmo que de um modo dificilmente acessível, a verdade, seja desta norma, quanto do senso.

...E com respeito às pretensões sociais sobre o indivíduo humano, hoje existem somente dois tipos de loucura: a unidade "racional" e a divisão "irracional", uma identidade defendida com pânico, e uma esquizofrenia ligada à angústia e ao terror (texto: Loucura - traduzido por Maurício Andrade - www.cisc.org.br). 


\section{5 - COMO A LOUCURA INSPIRA E GOVERNA AS PESSOAS NA VIDA E NO TRABALHO}

Conforme alguns pesquisadores a loucura comporta uma variável, ela pode ser consciente ou inconsciente. Nas corporações como nas relações sociais pode-se observar que algumas pessoas administram a própria loucura conseguindo dessa forma administrá-la pelo menos por algum tempo. Schereber (1) e Jamisson Kay (2) ilustram esses casos.

Existem corporações que desenvolvem um estilo de comunicação interna tão agressivo e invasivo, que exige do perfil de seus funcionários um grau permanente de estado alterado de consciência. Elas determinam que seus colaboradores adotem a sua filosofia dentro e fora da empresa e cumpram altíssimas metas. Dentre essas empresas se destacam as empresas que adotam o marketing de rede, telemarketing e nos bancos, os cargos, a partir da média gerencia. Nelas, conforme declara a psiquiatra Jamison Kay, os funcionários vivem as raias da loucura.

\section{6 - CONSIDERAÇÕES FINAIS}

O homem quando adentra o espaço organizacional é enredado pela comunicação normativa que governa os seus domínios. Essa comunicação através de normas implícitas e explícitas submete o homem através da persuasão necessária para que ele incorpore as suas características e adote para si os seus valores. Consciente do déficit que compõe a natureza humana, a empresa o seduz com benefícios que aí o prendem, manipulam e vigiam , utilizando- se dos símbolos de poder, conforme Pross.

Nômade em busca de novos territórios que possam prover as suas necessidades afunda-se como em areia movediça no complexo corporativo que promete atender as suas expectativas de satisfação. Tomado pelo poder de suas necessidades e da força da comunicação corporativa, o homem se submete, pois sabe que a qualquer falha sua poderá pagar com a exclusão. A submissão a essa cultura implica na adoção dos seus mitos, crenças, filosofia, e objetivos. O preço que o homem se propõe a pagar é o afastamento dos seus próprios valores e da percepção de si mesmo porque é totalmente absorvido pela empresa.

Quanto a esse mecanismo de incorporação nos jogos, Caillois explica que: "o homem se traveste do papel que representa e disfarça a sua personalidade para adquirir uma outra da qual incorpora as regras". Conforme foi visto, trata-se de uma atividade de imaginação e submissão contínua a essas regras que o autor chama de Mimicry ou mimetismo. Assim, pode-se considerar que na relação organizacional o homem disfarça a sua personalidade e incorpora a da empresa para representar os seus papéis. Ele lança mão do artifício da máscara que lhe permite a mudança da aparência e dessa forma, ocupa um lugar na empresa, semelhante ao que ocorre no jogo, ele se mascara e se traveste do outro que não é ele mesmo. E, no grupo de trabalho, como no teatro, ele interpreta dramaticamente, entrando no cenário proposto de fato e de direito. No campo de trabalho ele aproveita-se de todas as características do jogo: liberdade, convenção, suspensão da realidade espaço-temporal delimitada, a ilusão e a fé, como artifícios para executar a dissimulação de uma realidade e a simulação de outra. E assim, na representação, ele se dá ao prazer de se fazer passar pelo outro, não para enganar, mas para atingir objetivos propostos por ele e pela empresa.

$\mathrm{O}$ atendimento desse duplo objetivo exige o artifício da máscara e o homem se aproveita não apenas dela, mas da licença que ela lhe proporciona nesse ambiente para liberar um personagem do qual recebe o script e para a perfeita representação ele dissimula o seu eu.

Essas representações provocam euforia para uns e frustração para outros. Elas possuem características externas de representações, mas percepções internas de verdades. No percurso da análise pode-se observar que nelas os adeptos mudaram a estrutura dos seus vínculos, ou seja, os 
novos vínculos passaram a carregar em si características dos antigos. E, no seu estabelecimento, houve uma dupla contaminação, homem e empresa.

Diante dessa contaminação o funcionário se depara com o conflito de não ser ele mesmo nem o outro e nesse desamparo se perde, pois ele está negando seus padrões já estabelecidos com sentimentos e afetos (Sfez, 1994). O comportamento, resultante desse distúrbio de uma dissimulação que prometia ser perfeita, custa ao funcionário um esforço psíquico que deixa manifestar atitudes antagônicas mescladas das características dos dois simultaneamente. É importante ressaltar que esse processo de comprometimento não ocorre com todos os funcionários em uma empresa, e nem de forma generalizada em todas as empresas. Embora sejam apontados por vários pesquisadores e se manifestem em empresas de vários portes e em vários status da hierarquia organizacional não é uma regra geral.

Esse fenômeno se manifesta mais na classe média que nas classes populares, e é mais comum nos executivos e empresas de determinados tipos de trabalho, como, por exemplo, área comercial, especialmente marketing de rede. Ela exemplifica um maior índice de comprometimento, e as empresas de telemarketing seguem de perto o seu rastro de contaminação. A jornalista Roberta Belluomini da Rede Globo de Televisão, produtora de reportagem do Fantástico em São Paulo, apresentou no domingo, dia 09 de julho de 2005, uma matéria mostrando que todos os funcionários de telemarketing desenvolvem algum tipo de problema mental. Esse é promovido pela repetição da mesma informação na mesma tonalidade e frequência, ou seja, um ritual que promove os estados alterados de consciência. $\mathrm{Na}$ época, diversos profissionais entrevistados declararam que hoje as doenças profissionais deixaram de ser apenas físicas e se expandiram para as doenças mentais.

Essa disfunção, apontada por Morin como distinção/conjunção, ocorre no momento em que o homem faz o movimento de se diferenciar da massa e se identificar com a empresa. $\mathrm{O}$ fator acionador do processo é a pressão exercida pela comunicação organizacional através das normas internas e externas que governam as atitudes e comportamentos dos funcionários na empresa. Elas carregam em si os traços da norma social responsável pela lei e pela ordem. Originariamente elas são herdadas do mundo mitológico que compõe o imaginário humano e a cultura - a segunda realidade. Como herança mitológica traz em seu cerne os traços titânicos que oprimem os homens em suas obrigações e também as características da deusa Ananke, que, segundo Hillan, representa a necessidade.

Essa necessidade que empurra e atrai simultaneamente o homem para a empresa seduzindo-o com benefícios em troca do seu corpo e sua alma, não é arte apenas de Ananke, mas do departamento ideológico conforme explica Álvaro Vieira Pinto. Esse filósofo aponta na empresa o cérebro da manipulação capaz de fazer crer ao homem que a sua técnica, o seu saber e o poder do seu conhecimento, nada valem fora desse espaço mágico e mítico. Segundo o autor, esse espaço se coloca como aquele capaz de atender a todas as suas expectativas existenciais tanto em satisfação profissional existencial ou pessoal, pois aí homem pensa encontrar a felicidade. E dessa forma alienado ele aí se seda insano.

Os funcionários acreditam cegamente na promessa da empresa, e nessa fé submetem-se as normas com tamanha esperança de fazer da filosofia da empresa uma realidade que perdem o senso de realidade e corporeidade. De corpo e alma, rendidos, vivem a fantasia de riqueza e felicidade. Cegos para outras possibilidades vivem a suposta verdade a ela se entregando; como todos, crentes, tentam enredar outros a somar na sua loucura, pois o que mais aproxima da essência desta é a cegueira (Foucault, 1972:242).

Assim, a eles parece natural porque os loucos são aqueles que menos se dão conta da sua loucura. Dessa forma, a loucura na empresa é o mel que através da ilusão adoça as agruras da vida com a esperança e a fé, como sabiamente aponta Erasmo. Ela ocupa a mente dos seus agregados e dá trabalho ao corpo, submetendo-o a sacrifícios mortificantes em nome dos deuses, sucesso e riqueza, que governa o mundo contemporâneo. Assim, ignorando que esse corpo é 
cárcere da alma (KAMPER 2003), os homens passam a viver em dois cárceres, a alma presa ao corpo pelo sacrifício e ambos prisioneiros da rigorosa liturgia da empresa.

Essa forma eficiente de submissão promovida pela comunicação organizacional, através das normas corporativas subjuga os homens aos seus rituais, e como algumas perspectivas religiosas, prometem a felicidade no paraíso, com a vantagem de poder ser gozado na terra. Tomados pelo encantamento da promessa eles se entregam, se perdem entre a primeira e a segunda realidade, entram em delírio e nesse muitos permanecem.

Esse percurso implica em uma atividade de imaginação e submissão, um processo ritualístico apontado por Caillois. Nele o homem travestido ou mascarado "disfarça uma personalidade para, submetido pelas normas do jogo, incorporar uma outra". Essa incorporação permissão para o outro habitar o seu corpo - acontece na representação dos papéis; Foucault (1990:445) designa-a como loucura e lembra o provérbio "dos loucos se comanda as vontades". E não é isso que o departamento ideológico da empresa faz? Comanda as vontades? O autor explica que o conhecimento é uma forma de loucura e, paradoxalmente, a consciência de não ser louco, de estar fora da loucura, a consciência da não-loucura pertence ao sujeito do saber, único detentor da situação concreta e de base sólida sustentável (teoria) a partir da qual é possível conhecer a loucura. Sendo assim, é a partir da observação da prática, comparada com os conceitos teóricos, que se pode determiná-la na empresa.

A empresa através da comunicação interna se inscreve nos corpos, transformando-os em suporte das mensagens que deseja divulgar. Esses, submetidos, imprimem à mídia primária corpo - todo tipo de sacrifício - trabalho -, físico ou mental. Na liturgia religiosa esse procedimento - sacrifício -, é um ritual de purificação através do qual se atinge os estados alterados de consciência para se obter a revelação do alto, tornando-se um iluminado, aquele que se aproxima do reino dos céus. As empresas utilizam-se dessa estratégia para que os seus eleitos aproximem-se do reino da felicidade plena, o sucesso e a riqueza que o bem sucedido adquire na empresa, e em consequência do sucesso, torna-se objeto de desejo ou de amor de muitos. Ela se coloca no lugar da promessa na qual o homem quer acreditar, estimula a fé.

Assim, o homem, um ser alicerçado em crenças, mergulha na loucura que, aproxima-se da díade sano/insano com caráter de normalidade. E não é assim, comprometidos, que se apresentam os afiliados nas empresas? Como se pode observar o estilo de trabalho das empresas, e a sua exigência de dedicação, abre as portas para a loucura coletiva. A exigência da visibilidade ermanente impõe às pessoas uma situação de escravidão à sua cultura, filosofia e crença. Desta forma, os vínculos estabelecidos desde os primeiros contatos neste espaço, devoram o corpo e o tempo de vida dos filiados e de todos no seu entorno, comprometendo, inclusive, as suas relações sociais, afetivas e familiares. Assim afetados, os homens deliram, atuando e retratando um estado de loucura em seu aspecto concreto e imaginário.

Alienados de si mesmos abrem as portas para a loucura que, como sombra da razão, se instala. Assim a díade loucura/razão entra em relação, unificando homem e empresa. Os homens enredados e seduzidos pela promessa corporativa se agregam, coexistem entre conquistas e conflitos no entrelace da vaidade, da ambição e do desejo de status. Atraídos pelo cenário prometido, aprisionados pela ilusão dos imortais no reino dos mortos, os filiados da empresa tentam alimentar a sua condição ilusória e apaixonante de atingir os propósitos da empresa em um tempo-espaço sujeito à ventura (ambiente interno da empresa), destino da imagem; na expectativa da fortuna e da felicidade se perdem a procura de novos candidatos para juntar-se $a$ nau dos loucos.

\section{REFERÊNCIAS}

AGUIAR, M. A. F. Psicologia aplicada à administração. São Paulo: Excellus,2000. 
BAITELLO, N (1997). O animal que parou os relógios. SP: Annblume. 2a , ed 1999.

ATESON, Gregory. Steeps. To an ecology of mind. São Francisco: Chandler ed., 1972.

. La nouvelle communication. Paris: Seuil, 1988.

BYSTRINA, I. Tópicos de semiótica da cultura. São Paulo: CISC, 1995.

CAILLOIS, Roger. Les jeux et les hommes. Edtions Gallimard, (1958 1ª. Ed.) 1967.

CASSIRER, Ernest. Ensaios sobre o homem: introdução a uma filosofia da cultura humana

(Tradução Tomaz Bueno) São Paulo: Marins Fontes, 1994.

. Linguagem e mito. São Paulo: Ed. Perspectiva, Coleção Debates, 1972.

CHANLAT, J.F. O Indivíduo na organização. São Paulo: Atlas, 1993.

CONTRERA, Malena Segura. Mídia e pânico. São Paulo: Annablume, 2002.

GUIMARÃeS, L., PELEGRINI, M., SILVA, M. R. O espírito do nosso tempo. São Paulo, Ed. Annablume. 2004.

DEJOURS, C. A Loucura no trabalho: estudo de psicopatologia do trabalho. São Paulo: Cortez, Oboré, 5a edição, 1992.

EIBESFELDT, Eibl. El hombre pré programado. Spain: Ed. Alianza, 1973.

ELIADE, M. Images et symboles. Paris: Gallimard, 1980. Images et Symboles.París: Gallimard, 1980.

ELIAS, Norbert. O Processo civilizador. Vol I. Uma história dos costumes apresentação Renato J. Ribeiro. São Paulo: Ed. Jorge Zahar, 2000.

ERASMO, de Roterdam. Elogio da loucura. Paris: 1509 a primeira publicação. Rio de Janeiro: ed. Tecnoprint ltda.

FLUSSER, V. A Dúvida. Rio de Janeiro: Relume Dumará, 1999.

. Da religiosidade. São Paulo: Comissão Estadual de Cultura, 1967.

. Die Schrift. (A Escrita). Göttingen: Immatrix 4ª Ed., 1992.

. Fenomenologia do brasileiro: em busca de um novo homem. Rio de Janeiro: UERJ, 1998.

. Ficções Filosóficas. São Paulo: Editora da Universidade de São Paulo, 1998.

FONSECA, Alexandre Brasil. Evangélicos e mídia no Brasil. Bragança Paulista: Editora Universitária São Francisco, 2003. 
FOUCALT, M. A ordem do discurso. Trad. Laura Fraga de Almeida Sampaio. São Paulo ed Loyola, 2001, p. 43

. História da loucura. São Paulo: Ed. Perspectiva, 1990.

. Vigiar e punir. Petrópolis, Vozes, 26a. ed., 2002.

GASSET, José Ortega y. A rebelião das massas; tradução Marylene Pinto Michael, 2a. ed., São Paulo: Martins Fontes. (Título original: La rebelión de Las masas, 1a. ed. 1937, ed. EspasaCalpe. Argentina, Buenos Aires), 2002.

GEBAUER, Günter \& WULF, Christoph. Acessos miméticos ao mundo. Agir social, rituais e jogos e produções estéticas. São Paulo: Annablume, 2004.

HALL, EDWARD T. A dança da vida. A outra dimensão do tempo. Portugal, Lisboa: Relógio D’Água, 1996.

. A linguagem silenciosa. Portugal, Lisboa: Relógio D’Água, 1998.

HLADE A. P. Instituto Brasileiro de Direito de Família - IBDFAM. Disponível em http:// www.advocaciaconsultoria.com.br>.Acesso em 03 ago. 2005.

HILLMAN, James. Encarando os deuses. São Paulo: Cultrix/Pensamento, 1997.

. Paranóia. Petrópolis: Vozes, 1993.

HUIZINGA, J. Homo ludens. São Paulo: Perspectiva, 1996.

JAMISON, Kay Redfeild. Uma mente inquieta: memórias de loucura e instabilidade de humor. São Paulo: Martins Fontes 1998.

JUNG, C. G. Aion, estudos sobre o símbolo do si-mesmo. Petrópolis: Vozes, 1976.

. Os arquétipos e o inconsciente coletivo. Petrópoles: Vozes, 2000.

. O homem e os seus símbolos. Rio de Janeiro. Nova Fronteira s/d.

KAMPER, D. Wulf, C. Looking back on the end of the world. Nova York: Columbia University, 1989.

KAMPER, DIETMAR. A estrutura temporal das imagens. São Paulo: Revista Ghrebh-, 2002.

. O Trabalho Como Vida. São Paulo: Annablume, 1998.

. Loucura. Texto. Tradução de Maurício Andrade, www.cisc.org.br. COSPUCP, 2003.

complexidade. Porto Alegre, Sulina, 1997.

MARCONDES FILHO, C. A produção social da loucura, São Paulo: ed. Paulus, 2003.

Quem manipula quem? 2. ed. Petrópolis: RJ. Vozes, 1987. 
MCLUHAN, M. Os meios de comunicação como extensões do homem. 8a. ed. São Paulo: Cultrix, 1979.

MORIN, E. Ciência com consciência. Rio de Janeiro: Bertrand-Brasil, 1996. . O paradigma perdido. Portugal: Europa América, 2000.

MORRIS, Desmond. O macaco Nu. Trd. Hermano Neves. São Paulo: Circulo do livro, 1967, p. 112.

PRIGOGINE, Ilya. O Fim das Certezas. São Paulo: Edunesp, 1996.

PROSS, H. Sociedade do protesto, São Paulo: Annablume, 1997.

. Estructura simbólica del poder. Barcelona: Gustavo GILI, 1980.

PROSS, H. \& ROMANO, V. Atrapados em la rede de los medios. Orientación Em La diversidad. Hondarribia: Argitaletxe Hiru, 1999.

PINTO, Álvaro Vieira. O conceito de Tecnologia. Vol. 1. 2005, p. 444.

QUEVEDO, M. Introdução aos Sistemas Internacionais de Comunicação. D/M PUCSP, 2004.

ROMANO, Vicente. Desarrollo y Progreso: por una ecología de la comunicación. Barcelona: Editorial Teide, 1993.

. Tiempo y espacio en la comunicación. Hondarribia: Argitaletxe Hiru, 1999.

SAMAIN, Etienne. Temas básicos da sociologia, Programa de Pós-Graduação em Multimeios da UNICAMP. site: http://www.unr.edu.ar/. Acesso em 25/10/2003

SCHEREBER, D. P. Memórias de um Doente dos Nervos. Ed. P. Terra. Rio de Janeiro: 1995. SFEZ, Lucien. Crítica da comunicação. São Paulo: Loyola, 1994:13.

SERRES, Michel. A lenda dos anjos. São Paulo: Aleph, 1995.

Os cinco sentidos: filosofia dos corpos misturados. Rio de Janeiro: B. Brasil, 2001. SODRÉ, M. Antropológica do espelho: Uma teoria da comunicação linear em rede. Petrópolis: Vozes. 2002.

WINKIN, Yves. A nova comunicação: da teoria ao trabalho de campo. Campinas: Papiros, (Org. Etienne Samain), 1998.

YIN, R. K. Case study research. Califórnia: Sage, 1984. 